\title{
Infâncias e direitos na contemporaneidade: em foco as crianças do campo
}

\section{Children and rights in contemporaryity: focus on field children}

\section{Infancias y derechos en la contemporaneidad: centrarse en los niños del campo}

Franciele Clara Peloso*
Najela Tavares Ujiiie**

\section{Resumo}

Este estudo tem como objetivo refletir sobre as infâncias e as crianças, seus direitos e a constituição de suas identidades, considerando a pluralidade de espaços em que a infância acontece e dando destaque às crianças do campo. Trata-se de um ensaio teórico. A justificativa deste escrito está voltada à necessidade de problematizar, bem como dar visibilidade às diferentes infâncias e legitimar as experiências vivenciadas pelas crianças partícipes de contextos históricos marcados pela desigualdade social. As principais considerações deste estudo sublinham a coexistência de distintas infâncias e formas de ser crianças. Da mesma forma, evidenciam a invisibilização e o ocultamento de experiências infantis bem como a efetivação de direitos para crianças que foram segregadas ao longo da história e continuam sendo, quando homogeneizadas por uma concepção de infância de origem europeia, branca, cristã e urbana. A principal contribuição deste estudo consiste em problematizar junto às discussões relativas à infância a condição da experiência infantil das crianças no campo para que tenham seus direitos legitimados e a constituição de suas identidades reconhecidas com base na pluralidade de espaços em que suas vidas se fazem.

Palavras-chave: Infância. Criança do campo. Direitos.

\section{Abstract}

This study aims to reflect on childhood and children, their rights and the constitution of their identities considering the plurality of spaces in which childhood happens and highlighting the children of the countryside. It is a theoretical essay. The justification of this writing is focused on the need to problematize, as well as to give visibility to diferente childhoods and to legitimize the experiences lived by children who participate in historical contexts marked by social inequality. The main considerations of this study underline the coexistence of diferente childhoods and ways of being children. Similarly, they higlight the invisibility and concealment of children's experiences, as well as the realization of rights for children that have been segregated throughout history and continue to be homogenized by a conception of childhood of European, white, cristian na urban origin. The main contribution of this study is to problematize together the discussions related to childhood the condition of the children's experiencie in the countryside so that they have their rights legitimized and the constitution of their identities recognized from the plurality of spaces in which their lives are made.

Keywords: Childhood. Country Child. Rights.

Recebido em 14/10/2019 - Aprovado em 06/03/2020

http://dx.doi.org/10.5335/rep.v27i2.11424

Doutora em Educação pela Universidade Federal de São Carlos (UFSCar). Docente permanente do PPG em Desenvolvimento Regional da UTFPR, Campus Pato Branco, Brasil. Orcid: https://orcid.org/0000-0002-9647-001X. E-mail: fclara.15@gmail.com

** Pedagoga. Doutora em Ensino de Ciência e Tecnologia (UTFPR/PG). Professora Assistente da Universidade Estadual do Paraná, Campus de Paranavaí, Brasil. E-mail: najelaujiie@yahoo.com.br 


\section{Resumen}

Este estudio tiene como objetivo reflexionar sobre las infancias y los niños, sus derechos y la constitución de sus identidades considerando la pluralidad de espacios donde ocurre la infancia, poniendo énfasis en los niños del campo. Se trata de un ensayo teórico. La justificativa de este escrito está direccionado a la necesidad de problematizar, bien como dar visibilidad a las diferentes infancias y legitimar las experiencias vivenciadas por los niños partícipes de contextos históricos marcados por la desigualdad social. Las principales consideraciones de este estudio subrayan la coexistencia de distintas infancias y maneras de ser niños. Del mismo modo, ponen en relieve la invisibilidad y el ocultamiento de experiencias infantiles, bien como el cumplimiento de derechos para niños que fueron segregados a lo largo de la historia y siguen siendo cuando homogeneizados por una concepción de infancia de origen europea, blanca, cristiana y urbana. La principal contribución de este estudio consiste en problematizar junto a las discusiones relacionadas a la infancia la condición de la experiencia infantil de los niños en el campo para que tengan sus derechos legitimados y la constitución de sus identidades reconocidas a partir de la pluralidad de espacios en que sus vidas se hacen.

Palabras clave: Infancia. Niños del Campo. Derechos.

\section{Introdução}

Somos duas pedagogas, professoras/educadoras da Educação Superior, que se dedicam a pesquisas na área da educação da infância. Nossos processos formativos e também de pesquisa se desenvolveram em circunstâncias e com objetivos diferentes. Uma estudando os processos pedagógicos, mais especificamente, a formação de professores para educação infantil. A outra estudando especificamente a infância enquanto categoria filosófica bem como os distintos contextos em que as crianças constituem suas infâncias. Ao nos aproximarmos, iniciamos o diálogo e percebemos a intersecção de nossos estudos na área da educação da infância: a experiência das crianças, a garantia de diretos e a constituição de suas identidades.

Assim, objetivamos neste trabalho, que se caracteriza como um ensaio teórico, refletir sobre as infâncias e as crianças, seus direitos e a constituição de suas identidades considerando a pluralidade de espaços em que a infância acontece, dando destaque às crianças do campo.

Estudiosos da infância (FREITAS, 2011; FREITAS, KUHLMANN JUNIOR, 1998; SARMENTO, 2000 e outros) destacam que existem diferentes abordagens sobre essa temática, uma vez que cada contexto social, cultural e econômico é capaz de criar uma maneira particular de concepção a respeito desse tema. Nesse sentido, para realizar reflexões sobre as crianças e suas infâncias se faz necessário compreender essa fase da experiência humana de maneira global, não limitada aos seus fatores biológicos, e sim relacionada aos contextos em que a vida se faz em 
todas a suas nuances. Trata-se de uma temática que apresenta uma abordagem plural e multifacetada.

Frente ao exposto, podemos inferir que as formas de se relacionar com a infância resultam de uma complexa rede de valores e regras predominantes no ambiente ao qual ela está inserida. Müller (2007) afirma que o lugar social das diversas categorias de infância e, por consequência, de crianças, aparece a partir da ideia do que é naturalmente aceito ou considerado normal. A autora explica que, até o século XVIII, situações de pobreza ou riqueza eram consideradas autênticas e, assim, justificadas naturalmente às trajetórias distintas de crianças de diferentes condições sociais.

Contudo, é preciso afirmar que a concepção de normalidade a respeito da infância e das crianças nunca representou a totalidade de realidades infantis, uma vez que a infância das crianças brancas, de origem europeia, cristãs, urbana e de classes abastadas pautou e unificou, historicamente, a concepção de infância. Podemos citar aqui uma das obras clássicas escritas sobre o tema: História Social da Criança e da Família, de Philippe Ariès. Tal obra referenciou durante muito tempo os estudos sobre a infância. Na contemporaneidade as discussões a respeito dessa temática e os avanços na área de estudos sobre a infância (PINTO e SARMENTO, 1997; SARMENTO, 2000; 2008; ARROYO, 2008; 2012a; 2012b; MÜLLER, 2007 e outros) nos permitem ampliar o olhar e considerar diversas infâncias acontecendo simultaneamente em vários contextos geográficos. As infâncias e seus entornos ganham destaque por meio desses estudos que, além de expor e definir as concepções da infância, valorizam as experiências infantis, bem como empreendem denúncias e anúncios sobre as crianças e suas infâncias.

De maneira geral, a intenção desse escrito é contribuir para a ampliação desse campo de estudos ao problematizar sobre as infâncias, mais especificamente sobre as crianças do campo, no sentido de provocar uma discussão que oportunize refletir sobre o reconhecimento de seus direitos e a legitimação das identidades das distintas infâncias. Para tanto, num primeiro momento, abordamos as questões da infância e das crianças, numa perspectiva histórica, dando ênfase nos processos de constituição das concepções de infâncias. Na sequência, trazemos à baila a problematização sobre as infâncias do campo. Por fim, nas considerações finais, retomamos aspectos que julgamos primordiais discutidos ao longo do texto e afirmamos a urgência de se colocar no cenário das discussões relativas à infância a condição da experiência infantil das crianças do campo para que tenham seus direitos legiti- 
mados e a constituição de suas identidades reconhecidas a partir da pluralidade de espaços em que suas vidas se fazem.

\section{Infância e criança em foco: perspectivas contemporâneas}

A partir da modernidade, tendo em vista o crescimento das cidades, da população, do comércio, da inserção da mulher no mercado de trabalho dentre outros fatores, a infância começa a ser vista como questão social, política e educacional emergente. Alguns estudiosos e teóricos começam a se preocupar com a concepção de infância e de criança, surge o sentimento de infância (ARIÈS, 2006).

Com o sentimento de infância, surge também à preocupação com a educação da criança, seu bem-estar físico e social, sua formação integral para o exercício da cidadania. Kuhlmann Jr. (1998, p. 31) afirma que:

Pensar a criança na história significa considerá-la como sujeito histórico, e isso requer compreender o que se compreende por sujeito histórico. Para tanto, é importante perceber que as crianças concretas, na sua materialidade, no seu nascer, no seu viver ou morrer, expressam a inevitabilidade da história e nela se fazem presentes, nos seus mais diferentes momentos.

Assim, constata-se que a concepção de infância e criança tem relação direta com o contexto histórico, político e social. Kohan (2003) em uma abordagem filosófica evidencia que a infância se caracteriza por uma dinâmica de quatro momentos: 1) inferioridade - sujeitada e desnecessária; 2) superfluidade - pequena e sem função 3) possibilidade - projeção do adulto e futuro; e, 4) material da política - sujeito social e de direitos.

Pondera-se que o ser humano passa por fases ao longo de sua vida, sendo a primeira delas a infância. Nesse sentido, com base no Art. $2^{\circ}$ do Estatuto da Criança e do Adolescente (BRASIL, 1990), compreendemos infância como o período entre zero e doze anos de idade incompletos. A pessoa que está nessa fase é denominada criança, a qual é um ser em desenvolvimento físico, psicológico, intelectual e social, é dotada de direitos garantidos por lei, faz parte da sociedade e do contexto histórico, brinca, estuda, imagina, cria e é dotado de competências múltiplas.

Kuhlmann Jr, (1998, p. 16) pontua que a:

Infância tem um significado genérico e, como qualquer outra fase da vida, esse significado é função das transformações sociais: toda sociedade tem seus sistemas de classe de idade e a cada uma delas é associado um sistema de status e de papel. 
Frente ao exposto é contundente evidenciar que o contexto vivido e o período histórico têm forte influência na concepção de infância e criança que toma corpus. Nesse sentido, Lajolo (1997) é tenaz ao considerar que, hoje, existem tantas infâncias quantas forem ideias, práticas, discursos, que em torno dela e sobre ela se organizem.

De acordo com Oliveira (2002), etimologicamente a palavra "infância" é originária do latim (in-fans) e significa "não fala". No entanto, essa definição na contemporaneidade é inadequado, pois a leitura de mundo eminente nos dá a conhecer que o bebê tem capacidade de comunicar-se com outras pessoas por meio do choro, do sorriso e de gestos, além do que a fala estruturada é adquirida entre o segundo e terceiro ano de vida. Portanto, o infante contemporâneo e a criança têm fala, embora ignorada social e culturalmente por alguns.

A visão naturalizada de que a infância é um período específico, pelo qual todos passam, é que pode ser questionável, pois ser criança não significa necessariamente ter infância. Pode-se perceber que estamos num processo de alienação da infância: crianças pobres que precisam trabalhar e crianças da classe média e ricas que os pais as ocupam com inúmeras atividades que antecipam a fase adulta. É preciso oferecer à criança aquilo que lhe é próprio: o direito de brincar, criar e aprender.

A infância vem sendo alvo de frequentes estudos relacionados ao meio social onde está inserida. De acordo com Müller (2006), as concepções sobre a infância variam historicamente e as crianças ao serem parte da sociedade são mutantes, por um lado, adaptáveis, mas por outro, criativas e criadoras. Portanto, não podemos enquadrá-las como seres passivos, mas sim como agentes ativos que constroem suas próprias culturas e conhecimentos.

Nesse contexto, busca-se respaldo na Sociologia da Infância, na concepção de Sarmento e Gouvêa (2008, p. 11) que prima por "considerar a criança como sujeito que tem produção simbólica diferenciada produzida na interlocução com a cultura mais ampla, produção que define uma cultura infantil com identidade própria".

A infância, dentro desse enfoque, passa a ser concebida como uma categoria social geracional, isto é, sua ação no contexto de pertença não é passiva e fruto da reprodução da ordem social, é elaboradora, transformadora e produtora de cultura.

Nesse contexto, os personagens sociais envolvidos e implicados com a criança têm por compromisso político e pedagógico observar as interações infantis, analisá-las e concebê-las como fonte de apoio para a atuação consciente e intencional de educadores responsáveis pelo enriquecimento e diversificação dos repertórios das crianças, a fim de favorecer a construção da cultura da infância. 
A partir do final do século XX e início do século XXI, a criança e seu desenvolvimento passam a ter concepções valorizadas por estudiosos, entre os quais podemos destacar Steinberg e Kincheloe (2001, p. 12) que apresentam a seguinte afirmação sobre a infância no decorrer da história "é uma criação da sociedade sujeita a mudar sempre que surgem transformações sociais mais amplas".

Desse modo, a criança passa do anonimato para uma contextualização que a destaca como um sujeito histórico, construtor de identidade e produtor de cultura, que possui significações próprias do mundo diferenciando-se dos adultos. Sendo assim, a visão da sociologia da infância oferece reflexões que possibilitam o reconhecimento da criança como produtora de sua própria identidade.

Pode-se destacar que a infância é muito mais que um período vivenciado rapidamente pelas crianças é a fase na qual conquista sua aprendizagem e independência, independência que está relacionada à consciência de ser um sujeito que produz pensamentos e cultura. A infância é um tempo em si, com características, especificidades e vivências próprias.

Nesse sentido, Arroyo (1994, p. 91) afirma:

A infância já cidadã, é um ser vivo, é ser cultural já, é ser social já. E enquanto ser social que já é, na medida em que ela viver com mais intensidade e que ela é, estará se preparando para um dia viver com intensidade futuras idades, futuras fases de sua vivência, de sua formação.

Com base no autor supracitado, a infância não é categoria estática, é construção permanente, é categoria social. Dessa forma, tendo em vista a incorporação da educação infantil, como primeira etapa da educação básica, a partir da Constituição Federal (BRASIL, 1988) e da LDB 9394 (BRASIL, 1996), a nossa preocupação com a educação da infância deve se dar por compreensão da obrigação pública que temos frente à infância, considerando que a criança passou a ser sujeito de direitos e, consequentemente, o Estado passa a ter compromissos educacionais e sociais para com elas, bem como nós também enquanto profissionais implicados com a dinâmica educacional.

Como afirmam Sarmento e Gouvea (2008, p. 19), “ao estudar a infância, não é apenas com as crianças que a disciplina sociológica se preocupa, e sim com a totalidade da realidade social o que ocupa a sociologia da infância".

Sendo assim, se faz necessário entender as modificações ocorridas na trajetória da infância até a contemporaneidade e, nesta perspectiva, este texto prima por dar uma singela contribuição.

Corsaro, citado por Sarmento (2008, p. 29) afirma: 
As crianças, na sua interação com os adultos, recebem continuamente estímulos para integração social, sob a forma de crenças, valores, conhecimentos, disposições e pautas de conduta, que, ao invés de serem passivamente incorporados em saberes, comportamentos e atitudes, são transformados, gerando juízos, interpretações e condutas infantis que contribuem para configuração e transformação das formas sociais. Deste modo, não são apenas os adultos que intervêm junto das crianças, mas as crianças também intervêm junto aos adultos.

Pode-se afirmar que as crianças integram o meio social, constroem, interpretam e transformam essa herança cultural que é transmitida pelos adultos, são sujeitos determinantes e determinados.

O olhar das crianças permite revelar fenômenos sociais que o olhar dos adultos deixa na penumbra ou obscurecem totalmente. Assim, interpretar as representações sociais das crianças pode ser não apenas um meio de acesso à infância como categoria social, mas as próprias estruturas e dinâmicas sociais que são desocultadas no discurso da criança (PINTO, SARMENTO, 1997, p. 25).

Nessa dinâmica compreende-se que o preceito fundamental do estudo da cultura infantil, segundo os autores é a interpretação da autonomia da criança em relação aos adultos, que oportunizam significações próprias, estruturam e consolidam sistemas simbólicos.

Como evidencia Müller (2006, p. 557), “com certeza, as crianças realizam processos de significação que são específicos e diferentes daqueles produzidos pelos adultos". Pode-se, assim, definir cultura própria da criança como aquela interpretação realizada de forma imaginária, um mundo de fantasias, com significado condizente com sua inocência.

Contextualizando, na atualidade, a Sociologia da Infância volta seu olhar para a criança de forma que a vê como um ser que possui capacidade de construir sua identidade e de dar significado às mudanças que ocorrem no meio a que pertence, isto acontece por meio de suas experiências. "No caso das experiências das crianças nas sociedades contemporâneas são inegáveis as radicais transformações nas suas formas de inserção, revelando como a categoria infância vem sendo ressignificada" (SARMENTO, GOUVEA, 2008, p. 11).

Entretanto, Sarmento e Gouvea (2008) salientam que, ainda que a criança seja autora de sua forma de interpretação, também recebe influência das categorias geracionais, ou seja, a dependência daquilo que já está constituído pelas últimas gerações com as quais cria laços de pertença. São sujeitos de direitos e históricos determinantes e determinados pelo âmbito social e cultural de inserção.

Segundo Steinberg e Kincheloe (2001), existe uma cultura produzida para criança, a qual se funda na infância ainda como tempo de inocência e dependência 
dos adultos, explorando a fantasia e o desejo infantil, em prol de ideologias do mercado. E uma cultura da criança construída em um processo de produção corporativa criança-meio-adulto. A cultura infantil é, pois, constituída por elementos transmitidos e aceitos da cultura do adulto e elementos elaborados pelas próprias crianças.

Dentro dessa dimensão, as autoras e Müller (2006) apontam para a necessidade do reconhecimento por parte dos educadores da infância da cultura infantil, uma vez que seu entendimento tem ligação direta com as concepções que as crianças fazem do mundo, da vida e de si. Eis aí a importância da discussão fomentada, a qual primou por respaldar a compreensão de dar voz e vez às crianças dentro de seu contexto de pertencimento, a fim de balizar a proteção integral como foco e critério de validade para a infância, a criança e o adolescente no cenário social e educacional mais amplo.

Arroyo (2008, p. 134) em seus estudos bane a visão tradicional da infância e demarca:

[...] uma infância com voz, pensamento, cultura, autonomia, capacidade de fazer escolhas e de construir seu universo. [...] apresenta as crianças como atores sociais, morais e culturais plenos, consequentemente sujeitos da construção de suas formas de ser. As crianças não seriam passivas da conformação social de seu tempo, sofrem a diversidade de efeitos dos aspectos estruturais, mas também suas ações são estruturantes e através delas se autoconstroem.

Enfim, toda criança tem direito de ser criança, de ter infância e de ter uma educação de qualidade, comprometida com a cidadania e com a formação de uma sociedade democrática, que a reconheça como um ser social e histórico, pois, embora alguns progressos tenham acontecido em relação à criança, ainda há muitas conquistas a serem alcançadas e que perpassam pelo compromisso coletivo de agentes educacionais, jurídicos e sociais.

Frente ao exposto, podemos afirmar que na história sempre existiu distintas e diversas infâncias e formas de ser criança. No entanto, buscou-se, por muito tempo, generalidade de concepção sobre infância. A ideia de uma concepção genérica esteve vinculada junto aos estudos acadêmicos, à religião, à política, dentre outros campos. Essa concepção passou a ser dominante e desconsiderou aspectos como sexo, classe social, cultura, espaço físico e geográfico onde a criança vivia/estava, a relação estabelecida com as pessoas adultas, a época em que se era criança.

Pensar a infância na contemporaneidade é dar visibilidade às crianças que participam de diferentes espaços, que recriam outras culturas e, a partir disso, nos permitem outras compreensões de infância. Sob esse olhar, se faz necessário 
pensar e reconhecer outros tempos e espaços de produção da infância e educação das crianças, espaços que têm emergido como formas de organização da própria sociedade civil, bem como requerem pela garantia de seus direitos.

Nesse entender, tem-se a intenção de chamar a atenção para o fato de que as crianças, do e no Brasil, construíram história - com sua cultura, seus sofrimentos, sua desvalorização, sua exploração -, mesmo com a ausência de direitos que as tivessem como sujeitos principais, e algumas continuam construindo sua história e a história cultural do país em seu ocultamento, como as crianças que têm sua infância experienciada nos contextos do campo.

É importante citar, a partir das políticas públicas, quais são consideradas as infâncias do campo: agricultores familiares, extrativistas, pescadores artesanais, ribeirinhos, assentados e acampados da reforma agrária, quilombolas, caiçaras, indígenas e os povos e comunidades tradicionais (BRASIL, 2008). Como essas infâncias têm seus direitos garantidos?

Nossa intenção na próxima seção é ampliar essa discussão e problematizar sobre as infâncias, mais especificamente sobre as infâncias do campo.

\section{Infâncias e crianças do campo: alargando as perspectivas contemporâneas}

Pensar a criança em diferentes contextos como sujeito de direitos significa pensá-la na história, como sujeito que afirma sua identidade nas relações sociais e nos contextos de que participa. Sob essa perspectiva, é preciso reconhecer que a experiência da infância não pode ser padronizada, uma vez que tem características diferentes que variam de acordo com a classe social, com a cultura, com a etnia, com o gênero, com a experiência socioeconômica e política de cada sujeito em seu tempo histórico e da sociedade de que participa.

Mesmo com todo o esforço teórico proveniente de estudiosos da área (PINTO, SARMENTO, 1997; SARMENTO, 2000; 2008; ARROYO, 2008; 2012a; 2012b; MÜLLER, 2007 e outros) para explicar e compreender a situação da infância, a realidade apresenta muitas crianças desrespeitadas, oprimidas ou invisíveis em suas formas de ser e estar no mundo. Podemos dizer que existem, ainda, infâncias e crianças que são compreendidas a partir de uma concepção única permeada pela ideia de homogeneidade, que desconsidera a herança histórica de cada sujeito, bem como condicionantes econômicos, geográficos, culturais, sociais, étnicos, dentre outros aspectos que constitui suas identidades. 
Há crianças que não têm acesso ao atendimento mantido pelo Estado (considerando a política pública brasileira), seja ele de saúde, educação, assistência social, cultura, lazer e tantos outros. Essas infâncias não existem? Essas crianças não participam de processos de socialização ou os processos sociais de participam foram negados historicamente por não pertencerem à cultura branca, europeia, urbana $\mathrm{e}$ cristã? Como os direitos dessas crianças são assegurados na prática?

Diante disso, consideramos imprescindível pensar sobre como se dá a infância das crianças do campo e como se afirmam suas identidades. Essas crianças vivem e convivem em um cenário distinto, muitas vezes marcado pela dificuldade de acesso aos serviços oferecidos pelo Estado, tais como escola e saúde públicas.

Whitaker (2002) nos ajuda a afirmar que a infância do campo sempre existiu. A autora sinaliza que ao que concerne ao território brasileiro, talvez tenha surgido antes mesmo da infância urbana. A estudiosa afirma, ainda, que a ciência contemporânea é urbana-centrada e, a partir dessa raiz, estabeleceu padrões universais. Esses padrões criaram dicotomias hierarquizadoras, tais como masculino $\mathrm{x}$ feminino; cultura x natureza; urbano x rural; homem branco $\mathrm{x}$ homem não branco, dentre outros. Sob essa perspectiva, os estudos de Whitaker (2002) sustentam que o primeiro polo, de acordo com a ciência contemporânea é sempre valorizado em detrimento do segundo.

Com base na afirmação de Whitaker (2002), consideramos que a concepção de infância, aquela compreendida como universal ou generalizada, também foi construída no alicerce de uma cultura e/ou ciência urbano-centrada. Logo, a infância do campo ficou subjugada a essa concepção e não foi considerada a partir de sua realidade, de seu contexto e de seus sujeitos.

A partir dos estudos provenientes da sociologia da infância, conforme destacamos ao longo deste texto, podemos compreender a infância em sua pluralidade de condições, o que sugere o reconhecimento de diferentes formas de viver esse período da vida. Como parte desse reconhecimento, há também a certificação de categorias que demarcam a existência dessas diferentes infâncias, suas culturas, suas formas de ser e estar no mundo. Silva, Felipe e Ramos (2012) destacam que estariam incluídas nessas categorias: crianças pobres e ricas, africanas e europeias, brancas e negras, do campo e da cidade, dentre outras. Num primeiro momento, essa distinção pode parecer excludente, no entanto, seu reconhecimento nos permite ampliar o olhar para as diferentes infâncias; olhá-las a partir delas mesmas, de suas especificidades. Esse movimento, demarca a existência de cidadanias contemporâneas, as quais passam a requerer também a legitimação e/ou garantia de seus direitos. 
No que tange à garantia da cidadania na infância, vale destacar que se trata de uma construção que deve ter seu alicerce pautado na realidade das crianças, em sua individualidade, bem como ao seu grupo de pertença e experiências que se constituem na vivência cotidiana.

As crianças do campo estão inseridas em uma geografia específica e em uma rede heterogênea. Quando pensamos nessas infâncias, há algo que é comum a todas elas: fazem parte de grupos socioculturais historicamente excluídos, oprimidos, explorados. Por isso, aparecem no cenário social numa linha tênue entre a inclusão e a exclusão. Incluídas num processo de exclusão.

O campo é o espaço/território de vida, onde pessoas moram, trabalham, estudam e precisam ter sua dignidade reconhecida a partir do seu lugar, da sua identidade cultural. As relações estabelecidas no campo vão além da produção agropecuária e agroindustrial, do latifúndio e da grilagem de terras. O campo é lugar de relações, é espaço de camponeses, de quilombolas, de indígenas, de ribeirinhos e de todas as populações tradicionais do campo. No entanto, a história do campo brasileiro e dos povos do campo nem sempre foi compreendida, estudada e socializada como espaço de relações, de cultura e de produção de vida e de educação. Fernandes (2011) enfatiza que o campo deve ser concebido a partir de toda a dimensão humana que contempla, bem como das distintas formas de existência presentes nessa dimensão.

Quando pensamos, especificamente, nas crianças do campo, no contexto brasileiro, historicamente, podemos identificar infâncias que foram negadas e/ou invizibilizadas pela distribuição desproporcional das riquezas, tanto simbólicas quanto materiais. Essa situação produziu e produz condições sociais desfavoráveis para uma parcela da população. Essas condições sociais dizem respeito ao acesso a bens culturais, à educação formal de qualidade - desde a educação infantil, aos processos de socialização potencializadores de práticas humanizadoras. Poderíamos problematizar várias práticas dessas condições desfavoráveis, tais como: acesso à educação infantil (creche) para crianças do campo, transporte para chegarem até as escolas, alguns casos de falta de saneamento básico, acesso a diferentes conhecimentos culturais, dentre outros. Destaca-se, assim, a necessidade de pensar sobre essas infâncias, para que sejam reconhecidas suas marcas, sobretudo superados os processos que as submetem à exploração, à crueldade e, sobretudo, à negação de direitos.

Frente ao exposto, é possível afirmar que as populações do campo tiveram seus direitos sociais e humanos violados. No Brasil, esses direitos são garantidos pela 
Constituição de 1988 e, no caso das crianças, (re) afirmados no Estatuto da Criança e do Adolescente de 1990, bem como na LDB 9394/96. Os documentos citados operam em favor das crianças como sujeitos de direitos, que devem ser reconhecidos e consumados pela sociedade e pelo Estado. Esses documentos legitimam os direitos para todas as crianças em igual teor, no entanto, alguns estudos (ARENHART, 2007; SILVA, 2012; SILVA, 2013; ROSSETI-FERREIRA, 2012) denunciam que na prática as crianças do campo carecem ainda de terem seus diretos garantidos.

O reconhecimento das distintas condições em que a infância acontece nos permite autenticar a pluralidade de infâncias existente no campo, bem como reconhecer as crianças que participam desse contexto como aquelas que precisam ter seus diretos garantidos a partir do respeito à sua identidade. Essa autenticação denuncia a disparidade existente nas distintas formas de ser crianças e viver o período da infância. Consequentemente, os processos de humanização das crianças do campo são pautados na compreensão dessa realidade complexa, plural e desigual.

A desigualdade entre campo e cidade ainda são marcantes. As crianças do campo têm uma infância marcada, muitas vezes, pela falta de elementos básicos para seus processos de socialização. Dentre esses elementos, os mais precários e, por vezes, ausentes, é o acesso a serviços públicos de saúde e educação escolar, mesmo que existam políticas públicas específicas para ambas.

No caso dos processos de educação formal, a escola localizada no campo sofre com o descaso em relação a sua infraestrutura, desqualificação profissional e com o pouco investimento na implementação das políticas públicas (ARROYO, 2007; 2012a). Geralmente, as escolas do campo comportam classes multisseriadas e não têm profissionais para todas as demandas da instituição (zeladora/es, merendeira/os, corpo docente e gestão escolar). É preciso destacar que as discussões sobre a Educação do Campo contribuíram para a implantação de Políticas específicas e alavancaram a qualidade da educação que se oferece no e para o campo. Igualmente, promoveram estudos e abriram uma discussão sobre formação de profissionais coerente com as práticas do campo (ARROYO, 2007; 2012a). No entanto, é preciso destacar que essa discussão, bem como a implementação dessas Políticas de Educação do Campo ainda são incipientes.

Nesse sentido, a falta ou o não cumprimento do que preveem as políticas públicas fortalece a ideia de atraso a que o campo foi/é associado e, na mesma medida, invisibiliza seus sujeitos, seus processos de desenvolvimento e acesso aos bens materiais e culturais; logo, invisibilizam-se as crianças e desconsideram-se as distintas formas de viver a infância. 
Retomando as afirmações de Whitaker (2002), podemos inferir que, historicamente, houve a reprodução de uma hierarquia - do urbano sobre o rural. Morar no campo é sinônimo de inferioridade, de pobreza, de falta de instrução e de modernidade, de inferioridade social e cultural. Nessa relação complexa, marcada por forças ideológicas e políticas, a infância é afetada e as crianças marcadas por uma disseminação aviltante da vida no campo. As crianças do campo são chamadas de caipiras, peões, bregas, colonas, dentre outros termos. Além disso, a vida no campo é marcada pela sua desvalorização social nos espaços urbanos frequentados, públicos ou privados: supermercados, comércios, instituições escolares, dentre outros. Direitos para quem?

Stropasolas (2012) afirma que os processos de invisibilidade e exclusão marcam a condição social da infância no Brasil. Especificamente sobre as infâncias do campo, Arroyo (2012a) destaca que os estudos da infância passaram a denunciar a invisibilização de distintas formas de viver a infância na história. No entanto, o mesmo autor destaca que há infâncias tidas não apenas como invisibilizadas, mas inexistentes, cita como exemplo aquelas que pertencem a coletivos sociais, raciais e étnicos que não são reconhecidas como parte da história social, econômica, política, cultural e pedagógica do país.

A história social, política e cultural reconhecida e validada é aquela feita por e para algumas pessoas, geralmente brancas, de origem europeia, cristã e urbana. Essas pessoas são definidas pela história como racionais, cultas, laboriosas, enfim, superiores. As demais, aquelas que não são legitimadas no registro da história, são definidas como primitivas, improdutivas e irracionais. É preciso refletir sobre o acesso aos diretos de todas as pessoas subjugadas a esses processos excludentes e como a infância transita nessas relações tão enraizadas historicamente. Nesse sentido, questionamos, quais são os alcances e as formas que as crianças do campo encontram para exercer seus direitos? Destacamos aqui a necessidade de se pensar na efetivação dos direitos que, historicamente, foram negados às crianças do campo, de modo a respeitar a constituição de suas identidades, sobretudo o direito de legitimação da especificidade de suas infâncias.

\section{Considerações}

Esse escrito objetivou refletir sobre as infâncias e as crianças, seus direitos e a constituição de suas identidades considerando a pluralidade de espaços em que a infância acontece e dando destaque às crianças do campo. 
As reflexões feitas ao longo deste texto, transparecem a evidência de que, quando colocamos as infâncias do e no campo na esteira da discussão, somos convidados/ as a repensar nossas concepções. Conhecer as infâncias do campo nos possibilita construir outra discussão sobre a infância e seus espaços de experiência, legitimando a concretude histórica das crianças que constituem suas identidades nesses espaços. Nesse sentido, quando colocamos as crianças do campo e suas distintas infâncias nos holofotes, a história da infância ganha outras leituras, bem como, são outras as compreensões relativas aos direitos da população infantil. As leituras a que nos referimos se dão a partir de uma infância situada, real, menos abstrata, com outros tensionamentos. Uma infância que adquire outros significados e exige outras teorias para sua compreensão e problematização.

Encerramos esse artigo afirmando a necessidade de colocar no cenário das discussões as crianças do campo em suas infâncias e, dessa forma, colaborar para o registro de nossa história social e cultural, para a legitimação dos direitos dessas crianças e o reconhecimento do lugar onde suas identidades são forjadas. Acreditamos que, sem levar ao conhecimento os processos de marginalização, invisibilidade e inferiorização a que alguns grupos de crianças foram expostos durante nossa história nacional - e, como exemplo, podemos citar as crianças dos povos do campo em toda sua diversidade -, essa história é incompleta. É preciso problematizar as formas de socialização e construção da cidadania. Que direitos? Para quais crianças?

\section{Referências}

ARIÈS, Philippe. História Social da Criança e da Família. $2^{\mathrm{a}}$ ed. Rio de Janeiro: LTC, 2006. ARENHART, Deise. Infância, Educação e MST: quando as crianças ocupam a cena. Chapecó: Argos, 2007.

ARROYO, Miguel Gonzalez. O significado da infância. In: Anais I Simpósio Nacional de Educação Infantil: Conferência Nacional de Educação para Todos. Brasília: MEC/SEF/COEDI, 1994, p. 88-92.

ARROYO, Miguel Gonzalez. Corpos precarizados que interrogam nossa ética profissional. In: ARROYO, Miguel González; SILVA Maurício Roberto da. (org.). Corpo Infância: exercícios tensos de ser criança; por outras pedagogias. Petrópolis, RJ: Vozes, 2012b. p. 23-54.

ARROYO, Miguel Gonzalez. Outros sujeitos, outras pedagogias. Petrópolis, RJ: Vozes, 2012a.

ARROYO, Miguel Gonzalez. Políticas de Formação de Educadores (as) do Campo. Cad. Cedes, Campinas, v. 27, n.72, p. 157-176, maio/ago., 2007. 
ARROYO, Miguel Gonzalez. A Infância interroga a pedagogia. In: SARMENTO, Manuel Jacinto. GOUVEA, Maria Cristina de Soares. Estudos da Infância: educação práticas sociais. Rio de Janeiro: Vozes, 2008, p. 119-140.

BRASIL. Constituição da República Federativa do Brasil. São Paulo: Imprensa Oficial do Estado, 1988.

BRASIL. Estatuto da Criança e do Adolescente. Lei n $\square$. 8.069/90, de 13 de julho de 1990.

BRASIL. Lei de Diretrizes e Bases da Educação Infantil Nacional. Lei no 93494/96, de 20 de dezembro de 1996. Estabelece as diretrizes e bases da educação nacional. Diário oficial da uniãoBrasília- DF, 23 de dezembro de 1996.

BRASIL. Diretrizes complementares, normas e princípios para o desenvolvimento de políticas públicas de atendimento da Educação Básica do Campo. Brasília, DF: MEC, 2008.

FERNANDES, Bernardo Mançano. Diretrizes de uma caminhada. In: ARROYO, Miguel González; CALDART, Roseli Salete; MOLINA, Mônica Castagna. (org.). Por uma Educação do Campo. 5.ed. Petrópolis, RJ: Vozes, 2011. p. 133-145.

FREITAS, Marcos Cezar de. História Social da Infância no Brasil. 8ed. São Paulo: Cortez, 2011.

KOHAN, Walter. O. Infância e educação em Platão. Educação e pesquisa. Jan./Jun. 2003, v.29, n.1, p. 11-26.

KUHLMANN JÚNIOR, Moysés. Infância e educação infantil: uma abordagem histórica. Porto Alegre: Mediação, 1998.

LAJOLO, Marisa. Infância de papel e tinta. In: Freitas, Marcos C. (org.). História social da infância no Brasil. São Paulo: Cortez, 1997.

MÜLLER, Fernanda. Infâncias nas vozes das Crianças: culturas infantis, trabalho e resistência. Educação e Sociedade. Campinas, v. 27, n. 95, mai/ago 2006, p. 553-573.

MÜLLER, Verônica Regina. História de crianças e infâncias: registros, narrativas e vida privada. Rio de Janeiro: Vozes, 2007.

OLIVEIRA, Zilma Ramos de. Educação Infantil: Fundamentos e Métodos. SP: Cortez, 2002.

PINTO, Manuel. SARMENTO, Manuel Jacinto. As crianças: contextos e identidades. Braga: Centro de Estudos da Infância, Universidade do Minho, 1997.

ROSSETI-FERREIRA, Maria Clotilde. Prefácio. In: SILVA, Ana Paula Soares da. et al. (org.) Educação Infantil do Campo. São Paulo: Cortez, 2012. p. 21-24.

SARMENTO, Manuel Jacinto. GOUVEA, Maria Cristina de Soares. Estudos da Infância: educação práticas sociais. Rio de Janeiro: Vozes, 2008.

SARMENTO, Manuel Jacinto. Sociologia da Infância: correntes e confluências. In: SARMENTO, Manuel Jacinto. GOUVEA, Maria Cristina de Soares. Estudos da Infância: educação práticas sociais. Rio de Janeiro: Vozes, 2008, p. 17-39.

SARMENTO, Manuel Jacinto. Sociologia da Infância: correntes, problemáticas e controvérsias. In: Sociedade e Cultura 02. Cadernos do Noroeste, Série Sociologia. v.13, n.2, p. 145-164, 2000. 
SILVA, Ana Paula Soares da; FELIPE, Eliana da Silva; RAMOS, Márcia Mara. Infâncias do Campo. In: CALDART, Roseli Salete. et al. (org.). Dicionário da Educação do Campo. Rio de Janeiro, São Paulo: Escola Politécnica de Saúde Joaquim Venâncio, Expressão Popular, 2012. p. 417-424.

SILVA, Isabel de Oliveira e. et al. (org.). Infâncias do Campo. Belo Horizonte: Autêntica Editora, 2013.

SILVA, Ana Paula Soares da. et al. (org.). Educação Infantil do Campo. São Paulo: Cortez, 2012.

STEINBERG, Shirley. KINCHELOE, Joe L. (org.). Cultura Infantil: A construção Corporativa da Infância. Rio de Janeiro: Civilização Brasileira, 2001.

STROPASOLAS, Valmir Luiz. Os significados do corpo nos processos de socialização de crianças e jovens do campo. In: ARROYO, Miguel González; SILVA Maurício Roberto da. (org.). Corpo Infância: exercícios tensos de ser criança; por outras pedagogias. Petrópolis, RJ: Vozes, 2012. p. 153-183.

WHITAKER, Dulce Consuelo Andreatta. Sociologia Rural: questões metodológicas emergentes. São Paulo: Letras à Margem, 2002. 